* Mestrando em Direito na Universidade Regional do Noroeste do Estado do Rio Grande do Sul (UNIJUÍ)

E-mail: ionathanjunges@yahoo. com.br

** Doutora em Direito pela Universidade de Santa Cruz do Sul - UNISC/RS

Professora em Direito na Universidade Regional do Noroeste do Estado do Rio Grande do Sul (UNIJUÍ) e na Universidade de Santa Cruz do Sul (UNISC)

E-mail: rosane.cp@unijui.edu.br

\section{O PARADIGMA MODERNO E A RE(CONFIGURAÇÃo) DO SISTEMA DE JUSTIÇA A PARTIR DOS MECANISMOS ALTERNATIVOS DE JUSTIÇA}

THE MODERN PARADIGM AND THE RE (CONFIGURATION) OF THE JUSTICE SYSTEM FROM THE ALTERNATIVE MECHANISMS OF JUSTICE

Ionathan Junges* Rosane Teresinha Carvalho Porto**

Como citar: JUNGES, Ionathan; PORTO, Rosane Teresinha Carvalho. O paradigma moderno e a re(configuração) do sistema de justiça a partir dos mecanismos alternativos de justiça. Scientia Iuris, Londrina, v. 25, n. 2, p. 151-167, jul. 2021. DOI: 10.5433/21788189.2021v25n2p151. ISSN: $2178-8189$.

Resumo: O presente artigo tem por objetivo analisar a partir de uma perspectiva contemporânea o sistema de justiça e as mudanças que ocorreram no judiciário, principalmente em relação a expansão dos métodos alternativos de resolução de conflitos. Questiona-se: quais os fatores determinantes para a (re) configuração do sistema de justiça em relação aos paradigmas dominantes, e quais são as alternativas ao sistema de justiça? A hipótese é que com a modernidade e o surgimento do Estado moderno a partir do contratualismo assenta-se em uma forma de organização política, social e judicial que se complexou com o tempo. Com a mudança do tempo histórico e as transformações culturais que foram cruciais ao desenvolvimento de novos valores que forçosamente refletiram na (re)configuração do judiciário. Os novos métodos alternativos, principalmente em relação à justiça restaurativa é uma nova forma de compreensão e de relação entre os sujeitos sociais, aproximando de forma muito mais significativa com a cultura e a sociedade na luta pela pacificação social. Na construção do trabalho, utilizou-se o método dedutivo e como técnicas de pesquisa a bibliográfica e a documental.

Palavras-chave: contemporaneidade; punitividade; meios alternativos; justiça restaurativa.

Abstract: This article adopts a contemporary perspective to analyze the justice system and the changes that have occurred in the judiciary, especially in relation to the expansion of 
alternative dispute resolution mechanisms. Thus, it questions: what are the determinant factors for the (re)configuration of the justice system in relation to the dominant paradigms, and what are the alternatives to the justice system? The hypothesis is that modernity and the emergence of the modern State from contractualism, there is a form of political, social and judicial organization that has become more complex over time. The changes brought forth by the historical moment and cultural transformations were crucial to the development of new values that forcibly reflected in the (re) configuration of the judiciary. The new alternative mechanisms, especially in relation to restorative justice, are a new approach to understand and relate social subjects, bringing them closer together in a much more significant way with culture and society in the struggle for social pacification. In the development of this study, the deductive method was used by means of bibliographic and documental research techniques.

Key words: contemporaneity; punishment; alternative mechanisms; restorative justice. 


\section{INTRODUÇÃO}

O texto apresenta uma abordagem teórica no intuito de analisar as características do paradigma da modernidade e as relações com as mudanças que ocorreram no âmbito do sistema de justiça, que ao longo das últimas décadas, tem inclinado para o desenvolvimento de novas formas e técnicas de resolução de conflitos. O objetivo é analisar a partir de uma perspectiva contemporânea o sistema de justiça, tendo em vista a modernidade ocidental que desenvolveu uma estrutura política e jurídica no âmbito do Estado de direito e as mudanças que ocorreram nas últimas décadas, principalmente em relação a expansão dos métodos alternativos de resolução de conflitos. Por conta disso, questiona-se quais os fatores determinantes para a (re)configuração do sistema de justiça em relação aos paradigmas dominantes do sistema de justiça tradicional? Dito de outra maneira: quais são as alternativas ao sistema de justiça, principalmente ao sistema penal tradicional?

O artigo está estruturado em duas seções: na primeira é discutido a partir do horizonte teórico do paradigma moderno que tem no Estado de direito contratualista a construção de um sistema de justiça exclusivamente adstrito ao protagonismo da soberania do Estado, no âmbito do judiciário. Com o desdobramento de paulatinas mudanças nos valores compartilhados pela sociedade, sobretudo a partir da contemporaneidade, se estabelece novas formas de fazer e compreender o sistema de justiça na sociedade contemporânea, principalmente quando leva-se em consideração novas formas de resolução de conflitos. Dessa forma, na segunda parte, destacase a justiça restaurativa enquanto um novo modelo alternativo ao sistema penal tradicional que privilegia o encarceramento em detrimento de um novo olhar para o sistema tradicionalmente punitivista.

A hipótese do artigo é que com o surgimento da modernidade ocidental e o Estado moderno, a partir principalmente do contratualismo, configurou-se um modelo de organização político-jurídico que centralizou o protagonismo do sistema de justiça no âmbito estatal. Com a mudança do tempo histórico e das transformações culturais que desenvolveram novos valores na sociedade contemporânea forçosamente refletiram na (re)configuração do próprio sistema judiciário. Os novos métodos alternativos, principalmente em relação à justiça restaurativa é uma nova forma de compreensão e de relação entre os sujeitos sociais, aproximando de maneira muito mais significativa para o aprimoramento de uma cultura de pacificação social. Na construção do artigo, utilizou-se o método dedutivo e enquanto técnica de pesquisa a pesquisa bibliográfica e a documental.

\section{O PARADIGMA DA MODERNIDADE: DA PUNITIVIDADE A ASCENÇÃO DOS MEIOS ALTERNATIVOS DE JUSTIÇA NA CONTEMPORANEIDADE}

A modernidade é um projeto de mundo ocidental, têm suas origens na Europa sobretudo a partir do século XVI, quando marcou profundamente a compreensão do humano e de suas relações com a natureza. A partir da modernidade surgiram novos desdobramentos sociais, 
políticos e econômicos. O surgimento do Estado moderno (soberania, território e povo), trouxe o estabelecimento de novas relações no tocante à organização política e social privilegiando valores que ao longo da história foram paulatinamente reconfigurados com os novos desafios e complexidades da sociedade contemporânea. O objetivo deste capítulo é analisar o projeto moderno a partir de um estudo filosófico, destacando aspectos que configuram os paradigmas da modernidade, principalmente a partir da perspectiva de Bauman e Foucault que destacam mudanças importantes nas relações pessoais - de ser e poder - na sociedade contemporânea.

O grande projeto da modernidade confia a razão como "guia" que ilumina ${ }^{1}$ o progresso e o desenvolvimento humano através da ordem teleológica e universal. A racionalidade no pensamento moderno é a narrativa de uma grande estrutura que organiza e ordena o "cosmo" enquanto totalidade da compreensão humana e de sua relação com a natureza. Para Horkheimer e Adorno (1991), o projeto iluminista era a maneira de livrar o humano do mundo da metafísica e do feitiço, dissolvendo os mitos e atestar o mundo a partir da experimentação e da racionalização da natureza. Conforme Fensterseifer (1999) não tem referencia, no pensamento moderno a razão é caracterizada pelo modelo matemático que combinada a ciência e a experimentação preceitua uma série de procedimentos e técnicas pela qual o método passa a solidificar o estatuto da ciência. Enfim, no pensamento moderno, a razão é um modo de ordenar o mundo.

De acordo com Castro-Gómez (2007), o paradigma epistêmico que surgiu na modernidade pode ser datado entre o os anos de 1492 e 1700, pois na emergência deste paradigma torna-se hegemônico e universal a construção de um mundo que privilegia o indivíduo e a racionalidade. Se até o século XVI, a sociedade era organizada a partir de uma configuração organicista de mundo na medida em que a natureza, o humano e o conhecimento são partes integrantes de uma totalidade inter-relacionada, com a formação do sistema capitalista e da racionalidade instrumental corroborando de maneira decisiva na modificação dessa estrutura. Com a produção e a circulação de mercadorias voltadas para o acúmulo de capital e com o protagonismo do "império do indivíduo" enquanto centro do mundo, forma-se uma nova forma de compreensão do "cosmo", liderada agora por uma racionalidade de meio e fim que privilegia o sucesso individual.

Habermas (1997) considera que o momento contemporâneo é de abandono do paradigma da relação sujeito-objeto que tem dominado grande parte do pensamento ocidental. A racionalidade moderna é uma forma "reducionista" do próprio homem. Ao criticar a racionalidade instrumental, procura-se superá-la propondo em seu lugar a racionalidade comunicativa ${ }^{2}$. Esta, por sua vez, parte das interações entre os sujeitos linguisticamente mediatizados que se estabelece na comunicação cotidiana. $\mathrm{O}$ agir comunicativo é tentativa de reorganizar a sociedade a partir do paradigma da linguagem, enquanto um médium universal que estabelece a ligação intersubjetiva entre os indivíduos. Sem a invasão da racionalidade estratégica e burocrática desenvolvida na sociedade moderna, Habermas propõe a razão comunicativa no intuito de estabelecer acordos racionais intersubjetivos, indispensáveis para a reconstrução da sociedade moderna. Dessa forma, a razão

1 Referência ao iluminismo.

2 Quanto à racionalidade, em síntese, refere-se à "disposição por parte do sujeito falante e atuante de adquirir e utilizar um saber falível”. Ver também: Habermas (1990, p. 291). 
comunicativa é o fio condutor da reconstrução discursiva na qual estão inseridos o direito e a democracia.

A partir da contemporaneidade, Bauman (2002) considera que a sociedade moderna passou a assumir novas formas de configurações, tornando-se uma sociedade líquida que privilegia um mundo fluído e instável, no qual ocorrem constantes implosões de valores e de padrões até então estabelecidos. Se na fase sólida da modernidade, operada pela racionalidade e pelo fortalecimento das instituições e da ciência, na modernidade líquida, por sua vez, as instâncias mediadoras da vida humana, a comunidade, a religião, a cultura e a linguagem sofreram profundas desconstruções, formando um sujeito cada vez mais individualizado e produzindo um mundo de incertezas. Nessa perspectiva, Beck (2011) adverte que a sociedade contemporânea, ou a segunda modernidade, é composta de riscos na medida em que a humanidade está diante de mundo globalizado e de incertezas, transformado pelas inovações tecnológicas. Desse modo, criam-se novos cenários de riscos globais, seja em razão da ampliação dos riscos ou das incertezas em relação ao futuro.

O projeto moderno-iluminista orquestrou significativas transformações na forma de compreender e organizar o mundo, alterando substancialmente a relação do humano com as ciências, as artes e a cultura. Com as revoluções burguesas o projeto iluminista levou um discurso homogêneo que privilegia o indivíduo, considerado enquanto um sujeito autônomo e independente, além de um sistema econômico orientado excessivamente para o lucro e a instrumentalização da natureza por uma perspectiva metodológica e racional. Não obstante, o Estado de direito como se conhece hoje, é uma narrativa política e social que fora construída a partir do pressuposto de uma organização política e social que tem a legitimidade em agir em nome dos que compõe seu território ${ }^{3}$.

Para Ghisleni e Spengler (2011), existem duas visões fundamentais acerca do surgimento do Estado. A primeira visão compreende o Estado como uma criação artificial da razão humana, sendo o consenso uma forma de organização social. Por outro lado, a segunda concepção compreende que o Estado é um produto da sociedade na medida em que o desenvolvimento do Estado é necessário no sentido de poder manter a ordem e dirimir os conflitos. O poder soberano do Estado refere-se entre outras características a legitimidade em governar, legislar e decidir, normatizando as relações sociais, mediante o consentimento dos súditos, por intermédio de participação das escolhas dos representantes políticos.

$\mathrm{Na}$ visão contratualista, não se pode renunciar ao pacto estabelecido, pelo menos quando não há razões para isso ${ }^{4}$, e consequentemente cada um é responsável e autor do que o soberano faz. De modo geral, os contratualistas descrevem o processo de transformação das sociedades primitivas às sociedades atuais. Em comum, identificam o pacto social como princípio que estabelece os

3 A filosofia moderna privilegiou o indivíduo enquanto centro discursivo do mundo, tanto na epistemologia como na política. Neste sentido ver: Descartes (2000), Kant (2001). Em relação a filosofia política, o contratualismo identifica direitos individuais considerados naturais ao indivíduo corroborando o projeto moderno em centralizar o indivíduo. Por fim, interessante destacar a crítica sobre a racionalidade moderna principalmente as posições de Horkheimer (2002), Habermas (1997), Lucas e Santos (2019).

4 John Locke, no texto, segundo tratado sobre o Direito Civil, abre a possiblidade de Direito a resistência, na hipótese de um Estado opressor e ilegítimo. 
fundamentos da sociedade civil. Desta forma, a saída de um estado de natureza para a sociedade civil é pavimentada por acordos políticos e racionais que organiza e separa os poderes, priorizando os direitos individuais - Estado liberal. Em relação ao poder, o poder soberano é dotado de força coercitiva de aplicação imediata de recursos para a manutenção da ordem social. Dessa forma, o Estado é uma organização política organizada em regular e utilizar o uso das forças na medida em que monopoliza e legitima para si o seu uso.

Pra Hobbes (1999), o pacto social pressupõe que cada indivíduo renuncie a condição natural de liberdade e transfira a um único homem ou a uma assembleia de homens o poder de governar. Este corpo político formado a partir de um contrato é o poder soberano, que impõe aos súditos (população) todos os seus direitos, e que precipuamente garante uma convivência segura com seus pares. Neste sentido, o poder do Estado é exercido pela força para a manutenção da ordem e da paz social. Já em Locke (1973) o Estado é fundado por um pacto social que torna o Estado legítimo para resolver os conflitos entres os pares sociais, respeitando os direitos naturais que permeiam a existência humana (direito a propriedade privada, a liberdade e a igualdade jurídica). Dessa forma, no Estado moderno o sistema de justiça é exclusivo do monopólio do Estado, sendo previsto aos indivíduos os direitos fundamentais, como a liberdade, a propriedade e a igualdade.

Neste sentido o direito é um instrumento politicamente organizado para legitimar e organizar a ordem coercitiva na sociedade. Talvez daí a grande crítica marxista em relação ao caráter instrumental do direito e do Estado de Direito, que em últimas instâncias seriam um instrumento de violência e perpetuação do poder nas mãos da classe opressora. De qualquer forma, o que se observa é que no Estado democrático o poder de polícia e de coerção é tarefa e estatal, da mesma forma que o poder judiciário centraliza a aplicação do direito penal.

Dessa forma, Ghisleni e Spengler (2011), argumentam que a jurisdição enquanto poder do Estado, tem a função de cumprir obrigatoriamente o direito na medida em que possui legitimidade e autoridade para isso. A jurisdição é uma função estatal monopolizada pelo Estado de direito em que uma "terceira pessoa" imparcial em relação às partes deve decidir o conflito, subsumindo o caso concreto ao direito e resolvendo a demanda entre elas. Porém, esta forma de decidir conflitos, apesar de historicamente construída, não é considerada democrática, mas uma forma de soberania do Estado na convivência comum.

Para Pallamolla (2009) ao mencionar Foucault para referir-se a sociedade moderna e o paradigma da punitividade compreende o crime enquanto um perigo público. A modernidade formou uma "sociedade punitiva", um tipo de sociedade aparelhada pelo Estado que desempenha função estritamente corretivas em lugares especificamente determinados para realizar o processo de "transformação". Este "panóptico5" alimenta a sociedade punitiva através do controle das penitenciárias e da falsa ideia de justiça, orquestrado por um modelo de vigilância e controle social.

A proporcionalidade das penas é uma coisa moderna, somente a partir do Renascimento tornou-se as penas mais "racionais". Dessa forma, as penas de prisão se popularizaram nas sociedades modernas. Parte dessa cientificidade das penas está ligado ao positivismo e ao 5 É uma forma de vigilância e controle prisional, a expressão foi utilizada primeiramente por Jeremy Bentham. 
desenvolvimento das ciências da natureza, especialmente à física e à biologia, sem mencionar à matemática e a lógica, que tratou de enumerar métodos eficazes no controle dos corpos e da natureza. Parte do mundo moderno operou os fenômenos naturais a partir das mesmas lentes, o que favoreceu inevitavelmente o fortalecimento de uma ciência que prioriza o controle absoluto sobre sua experiência. Dessa forma tornaram-se instrumentos de métodos científicos na aplicação da punição (FOUCAULT, 2009).

Foucault (2009), em "Vigiar e punir" analisa as formas de punições que ao longo da modernidade paulatinamente sofreram mutações. Com as mudanças orquestradas por uma perspectiva reformista, surgiram em seu lugar verdadeiras técnicas e instrumentos utilizados pelo aparelho estatal, no caso das penas de prisões, que além de estabelecerem a relação entre o crime e o castigo, solidificaram o patamar punitivista da sociedade contemporânea. O movimento reformista tem por premissas em suas bases de justiça criminal os princípios e os fundamentos organizados por uma racionalidade técnica e instrumental de poder. A punição tem um caráter redistributivo, "pagar pelo o que fez", porém é necessário avançar nessa compreensão.

No modelo punitivo, deixa-se de priorizar o castigo físico (suplício) tornando-o em seu lugar, a prisão psicológica. A pena de prisão, apesar de contestada por alguns reformadores, torna-se um tipo penal recorrente no intuito de fornecer técnicas de punições mais proporcionais e menos excessivas, uma verdadeira "luta" entre o poder soberano e as ilegalidades promovidas pelo poder disciplinador. Dessa forma, o movimento reformista $[. .$.$] pensam dar ao poder de punir um$ instrumento econômico, eficaz, generalizável por todo o corpo social, que possa codificar todos os comportamentos e consequentemente reduzir todo o domínio difuso das ilegalidades (FOUCAULT, 2009, p. 93). Neste modelo, entra em cena outros elementos que reforçam as relações de poder que estão inseridas nas instituições sociais, como por exemplo, o presídio, a escola, o hospital. Por fim, o que se percebe é uma mudança de paradigma, de um sistema penal que em primeiro momento é adstrito ao suplício do indivíduo para um direito penal coletivo, à medida em que atinge a todos os corpos sociais de uma forma uniforme. Seu intuito é de alguma maneira controlar os comportamentos a partir das tecnologias de poder e de controle social dominante.

Conforme Pallamolla (2009), ao pensar uma forma de superar o direito penal tradicional e seu caráter punitivo, o abolicionismo penal é um modelo que destoa totalmente do sistema penal tradicional (punitivo), não compreendido enquanto "medida alternativa", mas enquanto um novo paradigma na forma de ver o crime. $\mathrm{O}$ abolicionismo penal de maneira geral tem o intuito de superar não somente a pena de prisão, mas as tradicionais formas punitivas. Suas críticas referemse principalmente em relação ao direito penal e a forma pela qual este trata os delitos. Parte desta crítica centraliza a ideia de que o crime em si mesmo não é composto por uma realidade "ontológica", mas são expressões dos conflitos sociais, ou seja, problemas causados no âmbito da própria sociedade e sua potencialidade em produzir a delinquência, e nesse sentido é evidente que o direito penal tradicional falha ao tentar a resolução de tais conflitos, somando o fato de ainda não desestimular os comportamentos delitivos. Longe de fazer justiça, o direito penal tradicional afasta a possibilidade do autor do delito "recuperar-se", além de deixar à vítima à mercê de qualquer 
tentativa de restauração penal.

De acordo com Diehl e Porto (2018) o abolicionismo penal, na compreensão de Hulsman ${ }^{6}$ e Nils Christie, é contrariar a forma de em que o sistema penal é exercido e centrado a partir do controle unilateral do Estado. Com influência dos movimentos de contracultura, que nos anos de 1960 fomentaram o movimento de uma nova criminologia, na medida em que eram constituídos por várias vertentes, advogam em favor desde o fim das penas de prisão ao mínimo penal, incluindo ainda a própria extinção do sistema penal. Compreendem o conflito de forma mais próxima da vítima, coisa que o sistema tradicional distancia ainda mais no curso do processo penal. Por fim, compreende que a complexidade do crime é muito maior que o caráter binário "culpado/inocente", sendo a pena de prisão "reprodutora da criminalidade".

Para Pallamolla (2009), o insucesso que as penas alternativas configuradas com base no modelo punitivo tradicional não é ignorado pelos abolicionistas penais, na medida em que defendem que as penas alternativas seguem os mesmos caminhos tradicionais do sistema penal, e por isso, apostam em um modelo alternativo ao sistema penal, em sua totalidade. O paradigma punitivista da sociedade contemporânea nem sempre predominou como forma de aplicação penal. A pena de prisão e sua aplicação tem poucos séculos na história. "Durante muito tempo predominaram as práticas de justiça comunitária, com o emprego corrente de técnicas não-judiciais e formas não-legais de resolução de conflitos, restando o Estado afastado destas questões" (PALLAMOLLA, 2009, p. 36). Desse modo, as resoluções de conflitos ocorreriam em outras esferas, não necessariamente judiciais, como é o caso predominantemente da competência atribuída ao Estado para a aplicação da norma penal.

Essa outra alternativa ao sistema tradicionalmente punitivo, possibilita um tratamento diferenciado em relação à vítima esquecida pelo direito penal e o processo penal, dando-lhe possibilidade de escuta e de participação (PALLAMOLLA, 2009).

Seguindo a mesma linha de raciocínio, mas pensando a partir da realidade norte-americana, observa-se transformações importantes no sistema jurídico e de justiça norte-americano, quando a partir do século XX com a crescente expansão, não apenas da discricionariedade da decisão judicial especialmente no âmbito civil, mas em relação aos movimentos de fomentar os modelos alternativos de resolução de conflitos.

De acordo com Chase (2014), tornou-se evidente o movimento de expansão da discricionariedade no âmbito do processo nas últimas décadas no Estados Unidos. A indagação do autor é que o conflito entre o Estado de direito e o uso livre da discricionariedade é paralelo ao próprio conflito que os valores norte-americanos sofreram sobretudo a partir do final do século XIX. O individualismo resultou na maior flexibilidade das escolhas compatíveis ao modelo de mercado eficiente e o igualitarismo que previa privilegiava um tratamento igual perante a lei, embora a resposta mais legítima em relação à justiça seja o reconhecimento da singularidade, representaria maior legitimidade ao próprio sistema de justiça.

Ainda para o autor são várias as causas para passagem do formalismo que perdurou

6 Ver também: Hulsman e Celis (1993). 
grande parte da realidade para um sistema mais flexível. De modo geral argumenta que o direito mais flexível e menos burocrático seja mais eficiente. Dessa forma, o novo modelo processual deveria ser científico, flexível e simples, porque o comércio e os negócios apresentam estas mesmas características. Essa nova imagem apresentada pelo Tribunais é também a representação da sociedade e dos valores norte americano. Sendo esta ordem social, um instrumento para o Estado de direito, fundamentado por instituições modernas, pragmáticas e eficientes (CHASE, 2014).

O individualismo contemporâneo reivindica uma infinidade de direitos e de formas de proteção. O Estado deixa aos indivíduos o poder de "autocontrole", ao retirar-se de uma participação mais efetiva no âmbito privado. Dessa maneira, "tivemos neste momento a passagem de uma sociedade vertical, a que nos habituámos a chamar uma sociedade de classes com pessoas no alto e com pessoas em baixo, para uma sociedade horizontal onde o importante é saber se estamos no centro ou na periferia". Com efeito, na contemporaneidade cada cidadão deve ser o seu próprio legislador, longe do paradigma positivista e dominante que caracterizou o formalismo, principalmente quando expressava claramente o "proibido" e o "permitido". Na contemporaneidade são cada vez maiores os processos de descentralizações das estruturas de poder e da interpretação judicial (GARAPON, 2001, p. 128).

Foucault chama a atenção para as novas configurações de poder que se estabeleceu na sociedade contemporânea. Se na modernidade ocidental, ou como menciona Foucault na sociedade disciplinar, o poder é centralizado pelo Estado, a partir dos séculos XVII e XVIII a descentralização do poder tornou-se eminente. Um conjunto de novas técnicas e tecnologias de poder essencialmente centradas nos corpos individuais e ao mesmo tempo no corpo coletivo. Essas novas técnicas não suprimem a técnica disciplinar, que fora imposta sistematicamente pelo poder centralizador, mas opera de forma complementar e está em outro nível, em outra escala, auxiliada por novos instrumentos. Se a primeira corresponde ao poder sobre o corpo, que opera-se de modo individualizado, precedidas por técnicas disciplinares de controle social, temos a partir das novas tecnologias de controle, uma segunda tomada de poder, que não é processada de modo individualizado mas, coletivo na medida em que opera não mais a partir da ótica do "homem enquanto corpo, mas na humanidade enquanto espécie de "biopolítica" do poder e da espécie humana (FOUCAULT, 2010).

Nesse sentido, mas a partir do pressuposto da sociologia, Bauman argumenta sobre a fragilidade e a flexibilidade das relações e dos laços comunitários que assola a sociedade moderna. Na sociedade líquida há desconstrução de toda a ideia de sólido, na medida em que a sociedade moderna, fundada sobre a égide da globalização, da acumulação do capital, da limitação do poder do estado e de uma individualização cada vez mais consistente, acaba por sua vez, criando uma sociedade de incertezas, especializada em grande medida no derretimento das configurações sociais estabelecidas (BAUMAN, 2007).

Apesar da maneira que Bauman aborda a questão da liquidez da sociedade moderna, ele oferece elementos importantes para compreender a re(configuração) social que passa a humanidade 
ocidental, de modo que estas novas relações repercutem também nas esferas políticas e jurídicas. Chase (2014) argumenta que a mudança apresentada no sistema de justiça norte-americano em prol de mecanismos ou técnicas alternativas de resolução de conflitos ao final do século XX possuem motivações institucionais, políticas e culturais. Estão alicerçados nos valores compartilhadas pela sociedade e sua desconfiança em relação ao Estado e sua ingerência no compartilhamento de uma vida comum. Dessa maneira contribui para promover o desenvolvimento e fomentar melhorias no sistema de justiça que correspondem aos valores e a cultura norte-americana, identificada pelo autor como o individualismo, o igualitarismo e o livre-comércio. Em conjunto, essas manifestações culturais modificaram a cultura jurídica norte-americana de forma que priorizou a expansão de medidas alternativas ao sistema judicial tradicional e punitivo. Ao analisar a relação histórica entre a mediação e a arbitragem observa-se a manifestação cultural em relação com o próprio sistema de justiça,

Enquanto a arbitragem envolve a tomada de uma decisão vinculante por um terceiro, na mediação este terceiro auxilia os litigantes a negociarem e atingirem a sua própria resolução [....] A mediação, devido à sua ênfase na resolução consensual da disputa, ganhou importância para aqueles que possuíam em elevada conta os valores do comunitarismo e da autodeterminação. Já a arbitragem é corriqueiramente encampada por interesses de mercado devido à sua potencial economia diante da jurisdição, à privacidade de que a decisão é cercada e à confiança no conhecimento especifico dos julgadores sobre espécie de questão ser decidida (CHASE, 2014, p. 136).

A mediação surgiu nas comunidades que tinham sua organização própria que cultivavam, por assim dizer, uma antipatia profunda pelo litígio, já a arbitragem se deu inicialmente pela classe dos comerciantes. Dessa forma, a mediação era indicada para as demandas consideradas por valores financeiros menores, ou para os hipossuficientes, já o mesmo não ocorreu com a arbitragem, que aceita pelo mercado não apenas como uma saída para o judiciário, mas principalmente para fugir das imprevisibilidades dos júris, e também como uma maneira de evitar o avanço do Estado sobre o setor privado. Dessa forma, tanto a arbitragem como a mediação também fomentam procedimentos privados como formas alternativas instituídas pelos próprios Tribunais (CHASE, 2014).

Garapon (2001), aposta na simbologia do papel da justiça para compreender as transformações que ocorreram na sociedade moderna. O sistema de justiça possui cada vez mais características democráticas, sendo a descentralização da justiça uma importante característica enquanto um "espaço simbólico" da democracia e que atinge também o sistema de justiça enquanto espaço social, seja por demandas individuais ou coletivas. A vertiginosa escalada das demandas judiciais é inédita até então na história e a complexidade do mundo se dá também nas esferas administrativas. Dessa maneira, à justiça torna-se simultaneamente mais simbólica e mais descentralizada. Nesses novos horizontes democráticos, novas alternativas ao sistema de justiça e de resolução de conflitos podem tornar-se novas formas de regulação social da própria sociedade, a partir de outros valores e princípios.

Para Cappelletti (1988), o conceito de "acesso à justiça" sofreu transformações importantes 
nos últimos tempos. Se o acesso à justiça no Estado liberal priorizava procedimentos extremamente formais e individuais que centram o indivíduo a possiblidade de buscar seus direitos, como pano de fundo tem o problema que nem todos têm a mesma possibilidade para propor suas demandas e acessar às instituições de justiça efetivamente. Nesse sentido, o acesso estritamente formal prejudica os sujeitos em buscar um acesso efetivo e menos formalista de justiça.

Apesar da igualdade formal, compreendida enquanto um direito fundamental do humano, verifica-se na prática verdadeiras (in)diferenças entre os litigantes no curso da justiça, privilegiando um sistema dogmático, formalista em desacordo com a realidade prática que dificulta inexoravelmente a igualdade das partes. Por outro lado, um modelo de acesso à justiça centrado na efetividade e na discussão menos formal, mas mais efetiva de acesso. $\mathrm{O}$ autor defende que o processo precisa reconhecer que as técnicas processuais devam servir a função social, isto é aproximar e não afastar os interesses dos que necessitam do sistema. Inevitavelmente um importante meio para configurar-se um acesso mais efetivo à justiça é que os meios judiciais clássicos não sirvam de modelo exclusivo de promoção de justiça, mas que sejam pulverizados e regulamentados por procedimentos que criam novos mecanismos alternativos ao sistema judiciário, alargando profundamente o próprio conceito de acesso à justiça (CAPPELLETTI, 1988).

Para Deborah Hensler, citado por Chase (2014), os modelos alternativos de justiça ganharam destaque principalmente a partir dos anos de 1990. Alguns dos tribunais federais e estaduais adotaram práticas de mediação para maioria das demandas civis. Assim, o próprio judiciário contribuiu para o estabelecimento de programas voltados para esta finalidade ao conferir, de forma ativa, proteção e compromissos acordados por particulares sujeitos aos meios alternativos. Isso tornou-se evidente à medida em que, nas últimas décadas, o processo normativo expandiu normas no intuito de promover os meios alternativos fomentando sua utilização.

Observa-se dessa forma, que ao longo do século XX, iniciou um processo de transformação do paradigma punitivo e judicializado centrado exclusivamente na figura do Estado, embora ainda de forma incipiente a migrar para novas formas e técnicas de resolução de conflitos, seja nas esferas civis ou penais. Esses mecanismos sinalizam mudanças importantes em promover de forma efetiva o próprio sistema de justiça ao relacionar-se de uma forma mais estreita com as partes, contribuindo de forma eficiente em estimular o diálogo e se possível obter o acordo entre os envolvidos.

Esses mecanismos de resolução de conflitos tendem a tornarem-se mais democrático na medida em que estimulam a participação mais efetiva das partes, contribuindo para o diálogo e a pacificação social. Ao diminuir o desgaste e o movimento de toda máquina judiciária que ao tratar estes casos apenas como "mais um", dificultam a reparação e o restabelecimento dos laços comunitários. Muito mais do que apenas outras formas de pensar à justiça, os meios alternativos revelam-se importantes para as sociedades democráticas, principalmente quando leva em consideração não apenas as demandas civis, mas também em relação ao direito penal. Neste sentido, tem-se observado uma abertura importante para abordar o direito penal a partir da perspectiva da justiça restaurativa, que paulatinamente expande no sistema de justiça brasileiro. 


\section{A JUSTIÇA RESTAURATIVA A PARTIR DA REALIDADE BRASILEIRA: POR UMA CONSTRUÇÃO DA POLÍTICA DA PAZ}

A justiça restaurativa tem por premissa facilitar o encontro entre a vítima e o ofensor, estimulando o diálogo entre os envolvidos, a reparação do dano e além disso, contribuir significativamente para o desenvolvimento social e para a cultura da paz (ACHUTTI, 2014). Dessa forma, postula a transformação social não somente em relação à justiça, mas em fazer justiça. A justiça restaurativa tem seu conceito aberto, pois dinamiza as diferentes experiências restaurativas. Na contemporaneidade, as práticas restaurativas associam-se com a ideia de um movimento relacionado a descriminalização, expandindo-se principalmente após os anos 90 em todas as etapas do processo penal (PALLAMOLLA, 2009).

A justiça restaurativa surge no Brasil nas primeiras décadas do século XXI, tendo uma matriz epistemológica americana/europeia, que destaca a concepção tripartida "encontro", "reparação de danos" e "transformação". No sistema de justiça brasileiro liga-se ao direito civilista como métodos alternativos de resolução de conflitos, enquanto instrumentos efetivos de pacificação social, solução e prevenção de litígios. Na prática opera enquanto um modelo alternativo de resolução de conflitos, com operações pré-processuais, processual e pós-processual, porém ainda adstrita ao processo, com inclinação especialmente procedimental servindo como um "desafogo" ao poder Judiciário, sendo norteados pelo princípio da celeridade e economia processual (CONSELHO NACIONAL DE JUSTIÇA, 2018).

A situação de fragilidade e ineficiência no sistema de justiça brasileiro, a dificuldade da justiça tradicional punitiva enquadrar os interesses das vítimas e os obstáculos na resolução dos conflitos, deixou claro a necessidade de fortalecer outros meios de acesso à justiça e de resoluções de conflitos como o da justiça restaurativa. Neste sentido, diferentemente do abolicionismo penal que propõe não apenar a alternativa a pena de prisão, mas a substituição da totalidade do sistema processual penal, a justiça restaurativa admite a utilização da pena de prisão para um número reduzido de delitos, observados a importância e a conservação das garantias processuais e penais (PALLAMOLLA, 2009).

A justiça restaurativa compreende que a justiça é um valor e não apenas um processo institucional. Ela opera na dimensão social priorizando a inclusão no âmbito de seus laços sociais, além é claro de formar e promover o próprio sistema de justiça. Ao aproximar-se do conflito e dos envolvidos busca-se aumentar a participação efetiva entre elas, ao realizar ações com o fito de restaurar os laços familiares e comunitários na tentativa de restabelecer, dentro do possível, os danos causados e com viés de compromisso com uma sociedade mais harmônica e mais segura (DIEHL; PORTO, 2018).

Para Braithwaite citado por Pallamolla (2009), considera que a justiça restaurativa representa uma radical transformação em relação ao sistema penal. Não apenas na forma de rever os mecanismos tradicionais e punitivas do direito penal, mas também enquanto uma maneira eficaz de transformar o sistema de justiça do mesmo modo que a vida das pessoas diretamente 
atingias por estes episódios, seja o ambiente familiar ou de trabalho. Os valores que a constituem não são estáticos, mas fluídos na medida em que estão sendo elaborados e modificados com base nas análises das experiências que conferem os resultados nas práticas restaurativas. Dessa forma, dado a abertura conceitual, as práticas restaurativas abrigam outras formas que por vezes não são denominadas restaurativas, mas que de alguma forma distanciam-se ao patamar tradicional do sistema de justiça, como destaca a autora:

Esta forma de fazer 'justiça', típica da modernidade, identifica determinada conduta como crime a partir de pressupostos que conferem a base à reação ao delito. Estes pressupostos, largamente presentes nas sociedades contemporâneas, vinculam-se ao paradigma da justiça retributiva e apresentam a seguinte ideia de crime e de justiça: a culpa deve ser atribuída; a justiça deve vencer, e esta não se desvincula da imposição da dor; a justiça é medida pelo processo; e é a violação da lei que define o crime (PALLAMOLLA, 2009, p. 68).

Contrapondo a tradicional justiça punitiva, centrada exclusivamente no poder do Estado em decidir o futuro da ação penal ou do crime, na justiça restaurativa acontece de modo diverso. Por intermédio de um processo colaborativo (mediador, infrator e ofendido) oferece uma importante ferramenta para a pacificação social. As práticas restaurativas são uma forma democrática de exercício de poder, por intermédio da participação mais efetiva dos envolvidos e de menor centralização do Estado. Ao ajudar a propor uma construção nas relações interpessoais ela promove a responsabilização do ofensor em se envolver e reparar os danos causados. Ao abster a centralidade do Estado e ao promover aos envolvidos no curso da resolução dos conflitos, a justiça restaurativa viabiliza a solução dos conflitos apostando nos interesses sociais coletivos, especialmente quando trata-se das verdadeiras raízes dos problemas sócias (FREITAS; POMPEU, 2019).

A justiça restaurativa constrói práticas nas esferas judiciárias ao fomentar "um novo olhar" seja nas relações familiares ou comunitárias. Com maior descentralização do sistema tradicional de justiça e com a participação mais efetiva ampliam-se os espaços democráticos, possibilitando a construção de um diálogo pacífico entre os envolvidos, importante para solidificar a cultura de paz. Com as práticas restaurativas e o aumento da participação das vítimas e dos ofendidos busca-se oportunizar em conjunto com as famílias e a comunidade a tentativa de uma verdadeira pacificação social. É uma forma de resolução de conflitos que destoa dos modelos de justiça penal tradicional, quando propõem a participação efetiva da vítima e do ofensor na resolução de seus conflitos; na reparação dos danos em favor da vítima (simbólica e/ou materialmente) e por fim, em não deixar de responsabilizar o ofensor, mas não de maneira excludente (DIEHL; PORTO, 2018).

Interessante destacar que parte da filosofia de Habermas adota um conjunto de características que fomentam discursivamente a legitimidade dos mecanismos alternativos de resolução de conflitos, ao considerar imprescindível, a racionalidade, o debate e o consenso nas esferas políticas, jurídicas e sociais do mundo comum. 
Habermas (1997) adota o princípio democrático como um elemento fundamental para a organização social e política da sociedade. Se a razão comunicativa é a condição que permite a intersubjetividade e o entendimento, o princípio é democrático na forma de realizar os atos políticos e sociais mediados por deliberações e consensos. A força legitimadora somente é possível a partir dos pressupostos das regras de comunicação que permite um entendimento ou um acordo alcançado entre sujeitos livres e iguais. A legitimidade é qualidade que uma norma tem em ser reconhecida em um ordenamento jurídico, ou seja, é um bom argumento que serve para demonstrar as próprias razões de um sistema político, se este pode ser considerado justo ou equânime (HABERMAS, 1983). Para o filósofo a legitimidade é “[...] é uma exigência de validade contestável; e que do reconhecimento factual dessa exigência que depende a estabilidade de um ordenamento de poder" (HABERMAS, 1983, p. 220).

Assim, por esta perspectiva os cidadãos exercem o poder em construir e implementar tentativas na mesma medida em que são simultaneamente autores e endereçados. Portanto, a legitimação se apoia em acordos comunicacionais dos integrantes de um discurso racional, sendo que estes devem propor sua manifestação acerca de uma norma. Desse modo, o direito assume uma forma democrática de produção, no qual a legitimidade das leis passa pela discussão pública tanto a nível da representatividade política quanto a nível da participação dos cidadãos na esfera pública, fundada na perspectiva de um princípio discursivo e democrático (HECK, 2009).

Por outro lado, não se pode deixar de fazer a crítica que no âmbito brasileiro a justiça restaurativa ainda reconfigurada a lógica estrutural de funcionamento dos sistemas de justiças, pois além das competências, a inclusão de novas situações depende de uma cadeia de poderes muito seletivos e burocráticos que acabam diminuindo a expansão do programa. Há outros fatores que impedem sua progressão. A resistências dos profissionais dos sistemas de justiça para expandir condutas consideradas graves ou de competência própria do sistema de justiça tradicional, ou ainda o princípio da indisponibilidade da ação penal (cuja titularidade pertence ao Ministério Público), razão pela qual os programas de justiça restaurativa apenas encontram oportunidade "processual" nos juizados especiais ou em atos infracionais. Neste contexto, as práticas restaurativas acabam, por assim dizer, completando a esfera judicial, e não tendo autônoma em relação aos métodos punitivos clássicos, tendo em vista aumentar a eficiência do sistema penal, principalmente quando se presta aos cuidados de casos simples e não graves (CONSELHO NACIONAL DE JUSTIÇA, 2018).

Ainda de acordo com relatório trazido sobre a justiça restaurativa no Brasil, observa que as pautas técnicas e legais referem a existência da previsão da resolução n. 225/16, do CNJ, que prioriza seu cabimento em fase pré-processual e a obrigatoriedade da suspensão do processo, assim como a eliminação da resolução que traz o princípio da celeridade, e o princípio da urbanidade, estendendo-se as pessoas do interior, e por fim, ao considerar abrir espaços para situações consideradas graves (tentativa de homicídio, estupro, roubo, tráfico de drogas) do mesmo modo que para questões ligadas à classe e ao gênero, além da importância em promover um debate público. Em síntese, desenha-se no Brasil um modelo próprio de justiça restaurativa, focado na 
responsabilização do ofensor, na prevenção e na pacificação de conflitos, e ainda na transformação das subjetividades e das relações intersubjetivas com alcance ainda muito limitado. Os desafios hoje são: a) buscar a superação dos elementos do paradigma punitivo na conformação da Justiça; b) progredir a autonomia das práticas restaurativas, face ao paradigma punitivo; c) fomentar a ampliação da base comportamental da justiça restaurativa, rompendo-se com a dicotomia criminal que estigmatiza as condutas (CONSELHO NACIONAL DE JUSTIÇA, 2018).

Dessa forma, a justiça restaurativa é uma alternativa ao sistema de justiça que privilegia o encarceramento e o tribunal, pois quem continua sendo encarcerado não possui "representação" e logo, seus interesses são reduzidos a estereótipos, cujo os resultados não poderiam ser os piores. No mundo paralelo a normalidade é operada sob a ótica de outra racionalidade que constrói um espaço social distinto dos domínios comuns. Nesta realidade a prisão e a morte não fazem mais sentido, quando não se tem mais nada, nada se tem a perder, são "apenas" mais alguns casos. Talvez apenas com um novo olhar reconfigurado, abre-se a possibilidade em pensar a transformação do sistema de justiça, não apenas em procedimento, mas de fato em valor. Talvez mais humanidade, e neste ponto a justiça restaurativa pode contribuir significativamente, mas é necessário um debate para se repensar o sistema de justiça que contribua de modo significativo para o diálogo e para a promoção de uma cultura da paz.

\section{CONSIDERAÇÕES FINAIS}

Por fim, verifica-se com o surgimento da modernidade a supremacia do Estado de direito com os fundamentos de um sistema político-jurídico orientados a partir da lógica contratualista enquanto organização política, social e judicial. A modernidade pulverizou a transformação social para um Estado de direito orquestrado na racionalidade instrumental, na centralidade do indivíduo e no acúmulo de capital, que com a complexidade das sociedades contemporâneas e dos desdobramentos das próprias críticas ao paradigma moderno, principalmente no tocante a racionalidade instrumental e a centralidade do Estado na resolução dos conflitos, ocasionaram transformações culturais importantes no desenvolvimento de valores que forçosamente refletiram na (re)configuração do poder judiciário, ou pelo menos na tentativa de mudar o paradigma ante exposto.

Na medida em que autoridade estatal judicial passou a ser desafiada através de um discurso que adstrita os valores democráticos somando com a autonomia cada vez mais cresceste frente ao discurso hegemônico e unilateral de fazer justiça centrado na soberania do Estado, iniciou-se ao longo do século XX um processo de transformação do paradigma punitivo e judicializado do Estado, embora ainda de forma incipiente a migrar para novas formas e técnicas de resolução de conflitos, seja nas esferas civis ou penais. Com a possibilidade destes mecanismos em tratar à justiça, e de relacionar com as partes, no intuito em estimular o diálogo e se possível, um acordo entre os envolvidos, mas também para que sejam ouvidos e dialogados com seus interesses e vontades, confrontando é claro com o outro lado.

Portanto, os novos métodos alternativos, principalmente em relação à justiça restaurativa 
é uma nova forma de compreensão e de relação entre os sujeitos sociais, aproximando de forma muito mais significativa na transformação cultural na luta pela pacificação social. Neste sentido, aparece enquanto resposta alternativa para o delito e a criminalização, ao utilizar outras técnicas em relação ao tradicional processo penal, atendendo aos novos valores que passam a ser considerados importantes para uma cultura de paz e da transformação da justiça social enquanto valor.

\section{REFERÊNCIAS}

ACHUTTI, Daniel. Justiça restaurativa e abolicionismo penal. São Paulo: Saraiva, 2014.

BAUMAN, Zygmunt. Modernidade líquida. Rio de Janeiro: Zahar, 2002.

BAUMAN, Zygmunt. Tempos líquidos. Rio de Janeiro: Zahar, 2007.

BECK, Ulrich. Sociedade de risco: rumo a uma outra modernidade. São Paulo: Editora 34, 2011.

CAPPELLETTI, Mauro. Acesso à justiça. Porto Alegre: Sergio Antonio Fabris Editor, 1988.

CASTRO-GÓMEZ, Santiago. Decolonizar la universidad: la hybris del punto cero y el diálogo de saberes. In: CASTRO-GOMEZ, Santiago; GROSFOGUEL, Ramón (org.). EI giro decolonial: reflexiones para una diversidad epistémica más allá del capitalismo global. Bogotá: Siglo del Hombre Editores, 2007. p. 79-91.

CHASE, Oscar G. Direito, cultura e ritual: sistemas de resolução de conflitos no contexto da cultura comparada. São Paulo: Marcial Pons, 2014.

CONSELHO NACIONAL DE JUSTIÇA. Relatório analítico propositivo justiça pesquisa direitos e garantias fundamentais: pilotando a justiça restaurativa: o papel do Poder Judiciário. [Brasília]: CNJ, 2018.

DESCARTES, Rene, Discurso do método. Lisboa: Edições 70, 2000.

DIEHL, Rodrigo Cristiano; PORTO, Rosane Teresinha Carvalho. Justiça restaurativa e abolicionismo penal: o poder judiciário no enfrentamento à violência contra mulher. Revista Jurídica Cesumar, Maringá, v. 18, n. 3, p. 689-709, 2018.

FENSTERSEIFER, Paulo Evaldo. A educação Física na Crise da Modernidade. 1999. 213 p. Tese (doutorado) - Universidade Estadual de Campinas, Faculdade de Educação, Campinas, SP. Disponível em: http://www.repositorio.unicamp.br/handle/REPOSIP/253704. Acesso em: 25 jun. 2020.

FOUCAULT, Michel. Em defesa da sociedade. São Paulo: Martins Fontes, 2010.

FOUCAULT, Michel. Vigiar e punir: nascimento da prisão. Petrópolis: Vozes, 2009.

FREITAS, Ana Carla Pinheiro; POMPEU, Victor Marcilio. Justiça restaurativa: sua legitimação pelo conceito de poder e Foucault, 2018. Revista de Direito da UFMS, Campo Grande, v. 4, n. 1, p. 262-278, jan./jun., 2019. Disponível em: https://periodicos.ufms.br/index.php/revdir/article/ view/5696. Acesso em: 23 fev. 2021. 
GARAPON, Antoine. Bem julgar: ensaio sobre o ritual do judiciário. Lisboa: Instituto Piaget, 2001.

GHISLENI, Ana Carolina; SPENGLER, Fabiana Marion. Mediação de conflitos a partir do direito fraterno. [recurso eletrônico]. Santa Cruz do Sul: EDUNISC, 2011.

HABERMAS, Jürgen. Direito e democracia: entre facticidade e validade. Rio de Janeiro: Tempos brasileiros, 1997.

HABERMAS, Jürgen. O discurso filosófico da modernidade. Lisboa: Dom Quixote, 1990.

HABERMAS, Jürgen. Para a reconstrução do materialismo histórico. Brasília: Brasiliense, 1983.

HECK, José N. Ensaios de filosofia política e do direito. Goiânia: UCG, 2009.

HOBBES, Thomas. O Leviatã. São Paulo: Nova Cultural, 1999.

HORKHEIMER, Max. Eclipse da razão. São Paulo: Centauro, 2002.

HORKHEIMER, Max; ADORNO, Theodor W. Textos escolhidos. São Paulo: Nova Cultural, 1991.

HULSMAN, Louk; CELIS, Jacqueline. Penas perdidas: o sistema penal em questão. Niterói: Luam, 1993.

KANT, Immanuel. Crítica da razão pura. Lisboa: Fundação Calouste Gulbenkian, 2001.

LOCKE, John. Segundo tratado sobre o governo civil. São Paulo: Abril, 1973. (Os Pensadores).

LUCAS, Doglas Cesar; SANTOS, André Leonardo Copetti. A (in)diferença no direito. 2. ed. Porto Alegre: Livraria do advogado, 2019.

PALLAMOLLA, Raffaella da Porciuncula. Justiça restaurativa: da teoria à prática. São Paulo: IBCCRIM, 2009.

Como citar: JUNGES, Ionathan; PORTO, Rosane Teresinha Carvalho. O paradigma moderno e a re(configuração) do sistema de justiça a partir dos mecanismos alternativos de justiça. Scientia Iuris, Londrina, v. 25, n. 2, p. 151-167, jul. 2021. DOI: 10.5433/21788189.2021v25n2p151. ISSN: 2178-8189.

Recebido em 23/02/2021

Aprovado em 02/06/2021 